tal, and doctor, and patient alike will be gainers by the change.

As this paper has already extended to some length, and embraced an important form of dropsy, viz., renal, 1 shall, with your permission, at some future period, direct attention to those other equally important dropsies dependent upon enlarged heart and diminished liver; and if not able to suggest much for their treatment, at least to state what is prejudicial. I remain, Sir, your obedient servant,

$$
\begin{gathered}
\text { Wymondham, Leicestershire, } \\
\text { March 30, 1842. }
\end{gathered}
$$$$
\text { R. DAY. }
$$

\section{RELIEF FROM CRAMP IN THE STOMACH BY VOMITING.}

\section{To the Editor of The Lancet.}

SiR,-I read in The LANCET of the week before last a letter from Mr. Graham, on a new method of curing cramp in the stomach ; and, in that of last week, a letter from Dr. Thompson, of Gower-street, commenting on Mr. Graham's communication, and stating that the practice of applying the cupping. glass over the region of the stomach for cramp in that viscus, although new to $\mathrm{Mr}$. Graham, was by no means a new practice, inasmuch as he was in the habit of applying that remedy to numerous patients whom he treated in his dispensary practice in the south of Ireland,-thus depriving $\mathbf{M r}$. G. of all originality in this mode of treatment. Now, in justice to Mr. Graham, I beg to state, that during the five years' apprenticeship which I served with an excellent practitioner in Ireland (a man who would not be ignorant, and who took good care not to be ignorant, of any method of treatment likely to benefit his patients) I never saw him apply the cupping-glasses in affections of the stomach, and never heard of any one else who did; at the same time I do not wish to contradict Dr. Thompson's statement. Such practice might have been adopted after my departure from that country; but I repeat it again, that during my residence in Ireland, I never saw the practitioner with whom I resided resort to this remedy, although he had two dispensaries and an excellent private practice, and he was not a man likely to have been ignorant of any new remedies either in Ireland or in any other country. With respect to this new remedy $I$ know nothing. As to the disease, having treated several hundred cases, I beg to say that I never found any remedy so efficacious as one I shall presently introduce. With the value of this remedy $I$ became acquainted in the treatment of the following case:-Mrs. E., residing in Worship-street, a lady of tall stature, fair complexion, and twenty-six years of age, was seized with violent cramp the stomach on the night of the 3rd of March, 1841. I saw her about two o'clock on the following morning. She was then writhing in the greatest agony; she had been subject to such attacks from time to time, but not of so violent a character as the present one; indeed, it was the most violent I ever witnessed. Such was the intensity of the pain that her screams were awful. When the cramp seized her, which was the case from time to time, the muscles of the whole body were violently contracted, and on one occasion of these attacks the body became bowed, as in opisthotonos, and it required three men to restrain her. The bowels were open, the skin moist, indeed bedewed with perspiration from exertion, but there was no fever; and on the subsidence of each attack all her faculties returned, and she appeared free from disease. In order to cure these spasms, the first dose I administered consisted of one hundred drops of laudanum, two drachms of tincture of assafoetida, sixty drops of aromatic spirit of ammonia, half a drachm of ether, and three or four drops of oil of peppermint, in some water. This dose was administered three times in the course of two hours, without benefit. I then bethought me of giving something to empty the stomach as quickly as possible, in order to relax this spasm. This something presented itself in the form of sulphate of zinc. I therefore administered a drachm of this salt dissolved in water, and in the course of a very short time had the pleasure of seeing the contents of the stomach thrown up, the spasm relaxed, and the patient free from pain by the discharge of wind, which rolled forth from her stomach like a mountain torrent, and I need scarcely add, cum murmure magno. I have treated her and several others upon the same principle since, and always with the same beneficial result. I remain, Sir, your obedient servant,

\section{IR. Davis, Surgeon.}

1, Worship-square, Finsbury, March 31, 1842.

CASE OF

\section{NASAL EN LARGEMENT} SUCCESSFULLY TREATED.

By Dr. Charles Clay, Mem. of the Roy. Col. of Phys., London; Lec. on Med. Juris. \&c., Manchester.

IN May, 1841, I was consulted by a young lady who had a peculiar enlargement of the nose, not accompanied with pain or inconvenience, excepting from the size; its appearance, however, was a circumstance to be considered: many different plans had been adopted, but without any effect. From the history of the case I suspected it arose from deficient menstruation, as those periodical 